\title{
Asymptomatic Bacteriuria in Pregnant Women in the Antenatal Booking Clinic at Aminu Kano Teaching Hospital, Kano, Nigeria
}

\author{
Kani Yamuna Aminu1, Umar Usman Aliyu2 ${ }^{*}$ \\ ${ }^{1}$ Aminu Kano Teaching Hospital, Kano, Nigeria \\ ${ }^{2}$ Aminu Kano Teaching Hospital, Bayero University, Kano, Nigeria \\ Email: ${ }^{*}$ drusmanaliyu@yahoo.com
}

Received 29 April 2015; accepted 25 May 2015; published 27 May 2015

Copyright (C) 2015 by authors and Scientific Research Publishing Inc.

This work is licensed under the Creative Commons Attribution International License (CC BY). http://creativecommons.org/licenses/by/4.0/

(c) (i) Open Access

\section{Abstract}

Asymptomatic bacteriuria is common in pregnant women and if untreated could lead to serious complications. Despite this, its prevalence and microbiological characteristics have not been well studied in Kano and they vary among different populations. The objective of the study was to determine the prevalence, microbiological characteristics and pregnancy outcome of asymptomatic bacteriuria in pregnancy among women who came for antenatal booking clinic at the Aminu Kano Teaching Hospital (AKTH) Kano. A cross sectional descriptive study was conducted among randomly selected 200 consenting pregnant women who came for antenatal booking from November 2010 to January 2011. Samples of $10-15 \mathrm{mls}$ urine were examined for pus cells and bacteria and then cultured on cysteine lactose electrolyte deficient agar. Colony counts yielding bacterial growth of $105 / \mathrm{ml}$ or more of pure isolates were deemed significant. Isolates were identified to specie level. Antibiotic sensitivity test was done, treatment was given and pregnancy outcome was determined. Urinalysis and Full Blood Count were done. The prevalence of asymptomatic bacteriuria in pregnancy was $\mathbf{9 \%}$. Parity and Pyuria had statistically significant association with asymptomatic bacteriuria $(\mathrm{P}<0.05)$. The commonest organisms isolated were Klebsiella spp. and Staphylococcus saprophyticus. Following treatment of asymptomatic bacteriuria, there was no statistically significant difference in pregnancy outcome compared to patients who did not have the condition. The incidence of asymptomatic bacteriuria in pregnancy in AKTH is low. Screening of pregnant women using urine microscopy culture and sensitivity should be reserved for pregnant women with higher risk of developing asymptomatic bacteriuria.

\footnotetext{
"Corresponding author.
} 


\section{Keywords}

\section{Asymptomatic Bacteriuria, Antenatal Booking Clinic, AKTH-Kano}

\section{Introduction}

Asymptomatic bacteriuria is bacteria present in urine in the absence of clinical signs or symptoms of urinary infection in the host [1]. Urinary Tract Infection (UTI) refers to both microbial colonization of the urine and tissue invasion of any structure of the urinary tract [2]. Bacteria isolated from the urine of patients with asymptomatic bacteriuria usually originate as colonizing flora of the gut, vagina, or periurethral area. Organisms then persist in the urinary tract without eliciting a host response sufficient to produce symptoms or cause eradication [1]. Variables, such as host genetic predisposition, incomplete bladder emptying, or the presence of a foreign body, may all facilitate persistence [1]. Escherichia coli is the most frequent organism isolated from subjects with asymptomatic Bacteriuria [3] and is responsible for at least 75 to 80 percent of cases [1]. Klebsiella pneumoniae, Proteus species, staphylococcal species, enterococci, and group B streptococci can also establish colonization [1] [2] [4].

A number of risk factors have been identified, which include: sickle cell trait or sickle cell disease; diabetes; immunosuppressive disorders; urinary tract obstructions (from stones); loss of bladder control (due to neuromuscular disease); and need for chronic instrumentation of the bladder [5]. Pregnancy enhances the progression from asymptomatic to symptomatic bacteriuria which could lead to pyelonephritis due to the stasis caused by the enlarged uterus. Pyelonephritis, in turn, can lead to adverse outcomes such as preterm labour, which is the most common cause of serious complications-including prematurity, low-birth weight, and higher fetal mortality rates [6] [7].

Adverse outcomes of concern have included the short-term complications of symptomatic lower tract infection or pyelonephritis, and longer-term complications, such as urolithiasis, genitourinary cancer, renal failure, hypertension, and death [1]. It has been found that the consequences of untreated asymptomatic bacteriuria such as pyelonephritis and premature labour in later pregnancy can be avoided by early detection in pregnancy and antimicrobial treatment [8] [9].

If asymptomatic bacteriuria is not treated, up to $30 \%$ of mothers will develop acute pyelonephritis [9]. The main goal of detecting and treating asymptomatic bacteriuria (ASB) in pregnant women is to prevent urinary tract infection (UTI) and its consequences. The value and cost effectiveness of routine screening for ASB is controversial. However, it is agreed that it is worthwhile in populations with high prevalence of asymptomatic Bacteriuria [10].

This study is therefore to determine the prevalence of asymptomatic bacteriuria in pregnant women attending antenatal clinic at AKTH, to identify the organisms involved, determine their relative proportions and their antibiotic sensitivities. The pregnancy outcome will also be determined following treatment of patients found to have asymptomatic bacteriuria, with the aim of making recommendations to improve obstetric practice.

\section{Methodology}

NULL HYPOTHESIS (H0)—The prevalence of asymptomatic bacteriuria amongst women presenting for ANC booking in AKTH is not high.

\subsection{Study Area}

Aminu Kano Teaching Hospital, Kano serves as a tertiary/referral health centre for Kano and its environs. The hospital operates specialist antenatal clinics four times a week seeing an average of 150 clients per clinic including 20 first time antenatal attendees who are booked or registered per day. The average gestational age at antenatal booking is twenty weeks.

\subsection{Design}

The study is a descriptive cross sectional study combining the use of interviewer administered questionnaires 
and analysis of urine and blood samples obtained from the study subjects.

\subsection{Study Population}

Inclusion Criteria

The study population was consenting pregnant women encountered at the antenatal booking clinic (first time attendants) of the Aminu Kano Teaching Hospital, Kano.

Exclusion Criteria

The following were excluded from the study

1) Patients who do not give their consent.

2) Patients with symptoms of urinary tract infection.

3) Patients who had antibiotics for any cause during the pregnancy.

\subsection{Sample Size Determination}

Sample size was determined using the formula:

$$
\mathrm{n}=\frac{\mathrm{z}^{2} \mathrm{pq}}{\mathrm{d}^{2}}
$$

where:

$\mathrm{z}=$ standard normal deviate at $95 \%$ confidence level for a normal distribution. It is 1.96 obtained from the normal distribution (z) table.

$\mathrm{p}=$ proportion or prevalence. For this study a prevalence of $8 \%$ obtained from a similar study done here in Kano. 21.

$\mathrm{q}=1-\mathrm{p}=0.92$ (complementary probability).

$\mathrm{d}=$ degree of precision of the estimate which is taken as 0.05 .

$$
\mathrm{n}=\frac{\mathrm{z}^{2} \mathrm{pq}}{\mathrm{d}^{2}}=\frac{1.96^{2} \times 0.08 \times 0.92}{0.05^{2}}=\frac{3.84 \times 0.08 \times 0.92}{0.0025}=113.05
$$

$10 \%$ was added to provide for attrition (or non response/loss of questionnaires) giving a minimum sample size of 125 clients.

The sample size was further projected to 200 (clients) to improve precision of the estimate.

\subsection{Sampling Technique}

A systematic sampling method was used for the purpose of this study. Using the formula for calculating sampling interval (sampling frame/sample size), a sampling interval of 3 each was used to select the required number of clients from the study facility in proportion with their average monthly ANC attendance of 320 clients, over a period of two months, giving a sampling interval of 3. If the client number three does not fall into the inclusion criteria, the immediate next client was taken for the study. The first client was selected randomly using a random number table. Only clients that satisfy the inclusion criteria for this study were recruited.

\subsection{Study Instruments}

Semi structured, interviewer administered questionnaires were used to collect information about bio data, history and examination findings, laboratory investigations and pregnancy outcome.

\subsection{Specimen Collection and Processing}

The urine and blood samples were collected from the antenatal clinic of the Department of Obstetrics and Gynaecology. The urine samples were collected by the clients in a sterile container and processed in the Microbiology Laboratory while the blood samples were collected by the laboratory technicians under the supervision of laboratory scientists and were analyzed using an auto analyzer in the haematology laboratory of AKTH.

All pregnant women who came to the antenatal booking clinic at AKTH and who agreed to enter the study were clinically evaluated to exclude signs and symptoms of UTI and prior use of antibiotics for any reason in the 
index pregnancy. With the aid of a questionnaire, demographic features including age, parity, and gestational age of pregnancy were collected. A general physical and abdominal examination, including Sympisio-fundal hight (SFH) measurement were done and the findings recorded. Ultrasound scan was utilized for dating in cases of unsure date. The socio economic level/status of the patients were assessed on the basis of patient's highest educational level and husband's occupation using the classification by Olusanya O, Okpere E and Ezimokhai, M [11]. The patients were followed up after one week and those confirmed to have asymptomatic bacteriuria were treated based on the antibiotic sensitivity pattern of the isolated organisms. A repeat urine culture was done one week after treatment to confirm cure and to retreat those with persistent asymptomatic bacteriuria. They were then followed up with monthly urine checks until delivery, when the pregnancy outcome was also determined.

Transportation of samples:

Urine samples were immediately transported (within one hour of collection) to the laboratory in the designated containers. Blood samples were transported to the haematology laboratory for auto analysis using an auto analyzer.

The urine samples were placed in a cold box away from sunlight and transported to the microbiology and parasitology laboratory.

\section{Laboratory Processing of Urine}

This was carried out with the assistance of the laboratory physician, scientists and the laboratory technicians. The researcher initially observed how the urine processing was done and subsequently took part in the processing of the samples under the supervision of the laboratory physician. The researcher was also there during the reading of the culture and sensitivity results to ensure accuracy.

\subsection{Sterilization of Media and Materials}

The media used included Cystein Lactose Eletrolyte Deficient (CLED) Agar and blood agar supplied by Oxoid Limited, Muller Hinton agar by Liofil Chem. Italy, antibiotic sensitivity discs (G-XXI-minus octa discs supplied by Hi Media Laboratories Pvt. Limited), single antibiotic impregnated discs by Oxoid Ltd., UK and Combo Stik 10 urinalysis strips supplied by Dong Bang Acu Prime Limited.

All glass wares were washed with detergent and rinsed with water, then allowed to dry. The glass wares were later wrapped in aluminum foil and sterilized in a hot air oven at $160^{\circ} \mathrm{C}$ for 3 hours.

\subsection{Macroscopic Examination}

The urine samples were first examined macroscopically to observe for colour turbidity and presence of blood clots or debris. The samples were then divided each into three portions, for microscopy, culture and chemical analysis. This was to avoid contaminating the urine samples.

\subsection{Microscopy}

About 5 mls of urine samples were mixed and centrifuged at 5000 Rpm for 5 minutes. The sediments obtained were placed on a glass slides and covered with cover slips and viewed under high power field using both $\times 10$ and $\times 40$ objectives to examine for pus cells which indicates the presence of bacteria, presence of motile bacteria, schistosoma ova, trichomonas vaginalis, red blood cells and casts of red blood cells, white blood cells and hyaline granular casts. Also noted was the presence or absence of fungal yeast cells and crystals. Samples with 10 pus cells $/ \mathrm{mm}^{3}$ or more were regarded as pyuric. Drops of the urine samples were applied to glass microscope slides, allowed to air dry, stained with gram stain, and examined microscopically(primary gram staining). Presence of at least one bacterium on gram stain is considered significant. Quality control was done with control strain of staphylococcus aureus (for gram positive organisms) and Escherichia coli (for gram negative organisms).

\subsection{Culturing of Bacteria from Urine Samples}

From the sterile containers, a sterile calibrated wire loop delivering $0.002 \mathrm{mls}(0.002=1 / 500)$ of urine was used to streak onto the blood agar plates from one end of the plate to the other, and then used to streak it across the 
line to spread it sideways. This was done to test for significant bacteriuria.

Using the sterile calibrated wire loops, the specimens were streaked onto CLED agar plates for colony characterization, identification and antibiogram. Both plates were incubated at 37oc for 18 - 24 hours.

After incubation, the blood agar plates were observed for confluent growth which indicates significant bacteriuria, and if not confluent, the colonies were counted and multiplied by the size of the inoculums of the calibrated wire loop which is 1/500. Bacterial value of greater than or equal to 105 is considered significant. For cultures with no or insignificant growths, incubation was continued for a further 24 hours before conclusion of a negative culture result was reached. A repeat urine sample collection was done for contaminated samples.

Colonies from CLED plates were characterized if mucoid or not and for evidence of lactose fermentation. After colonial description, pure colonies were subjected to gram stain (Secondary gram stain). Gram negative bacilli are more likely to be Escherichia coli, Klebsiella, pseudomonas or proteus while gram positive cocci are more suggestive of staphylococcus species.

Biochemical tests are performed from the pure colonies for identification according to standard procedure. Escherichia coli was found to be motile, indole positive citrate negative and triple sugar iron agar (TSIA) reaction was acid/acid-slope/butt whereas Klebsiella was identified as gram negative bacilli, indole negative, non motile, slow urease positive. Staphylococcus saprophyticus was identified as gram positive cocci in clusters, catalase positive but coagulase negative.

This was followed by antibiogram determination, using pure colonies from the CLED agar plates. This was determined using Muller Hinton agar plates, pure colonies from control strain organisms-Staphylococcus aureus (ATCC 25923) and Escherichia coli (ATCC 25922), Mc Farland's standard, sterile swab sticks and antibiotics discs.

Three well isolated pure colonies of similar appearance from the isolates, and control strain (Escherichia coli ATCC 25922) for Klebsiella and Escherichia coli and Staphylococcus aureus (ATCC 25923) for Staphylococcus saprophyticus, were emulsified in separate $4 \mathrm{mls}$ of physiological saline each, labeled Test and control for each organism isolated. The turbidity of the suspensions (both test and control) was compared to 0.5 Mc Farland's standard.

Muller Hinton agar plates for both test and control streaked with test and control suspensions respectively using sterile swabs. After five minutes, sterile forceps was used to place the antibiotic discs evenly in both the control and test plates (similar antibiotics were used for both the test and the control), according to Kirby-Bauer disc diffusion technique.

Within 30 minutes of applying the discs, the plates were incubated at 35 - 37 oc for 18 - 24 hours. After overnight incubation, both the test and control plates are examined. Using a ruler on the underside of the plates, the diameter of each zone of inhibition was measured in millimeters.

For interpretation, the zone diameter of each antibiotic of the control was compared with the Clinical Laboratory Standard Institute (CLSI) standards. If within the CLSI acceptable limits for quality control strains, then the zone diameter of each antibiotic of the test were compared with the CLSI zone diameter break points and was recorded as sensitive, intermediate and resistant.

The octa discs used contained chloramphenicol (C) 30 mcg, Ampicilin (A) 10 mcg, tetracycline (T) 30 mcg, Gentamycin (G) 10 mcg, co-trimoxaxole (Co) 25 mcg, ceftriaxone (Ci) 30 mcg, cefuroxime (Cu) 30 mcg, ciprofloxacin (Cf) $5 \mathrm{mcg}$. Single discs impregnated with the following antibiotics were also tested: Augmentin 30 mcg (Aug), ceftazidime $30 \mathrm{mcg}$ (Caz), cloxacillin (Cxc) 5 mcg and nitrofurantoin (N) $300 \mathrm{mcg}$.

Urinalysis: A urinalysis was done, using Combi 10 reagent strips, using the third portion of each of the urine samples. This was used to specifically look for the presence or absence of protein, glucose, leukocyte esterase and nitrite. Other parameters noted were the presence or absence of blood, bilirubin, urobilinogen, ketones, the $\mathrm{pH}$ and specific gravity.

Full blood count: Full blood counts were done with an auto analyzer in the haematology laboratory using about 2 mls of blood collected each from the clients into the Ethylene di ethyl amine (EDTA) bottles.

\subsection{Data Management/Analysis}

The data was entered into a personal computer using Microsoft excel soft ware and analyzed using statistical package for social sciences (SPSS) version 16 computer software. Prevalence of asymptomatic bacteriuria in pregnancy was estimated together with $95 \%$ confidence interval. 
Means were compared using the t-test and proportions were compared using the Chi square test where applicable. Significance was considered at a p-value of $<0.05$.

\subsection{Ethical Consideration}

Approval for the study was obtained from the hospitals ethical committee and informed consent was obtained from the clients after adequate information with respect to the purpose of the study, objectives, procedure, risk/discomfort and potential cost/benefit.

For those found to have asymptomatic bacteriuria, the test was repeated after one week of treatment to confirm cure and thereafter monthly till delivery to detect possible re-infection.

Participation of clients in this study was voluntary. Respondents were assured of confidentiality and the questionnaires did not bear their names. The provision of the HELSINKI declaration on the investigation of human subjects was respected.

Limitations: The limitation of this study was that some of the clients had difficulty in obeying guides as to the production of a clean catch specimen giving room for contamination by commensal organisms. Thus adequate explanation was given to the clients to reduce the chances of this limitation.

Another limitation was that multi discs were used concomitantly with single discs due to low availability of the single discs, instead of the standard single discs that are used solely nowadays.

\section{Results}

Two hundred pregnant women were recruited into the study at booking. Sixteen case folders could not be traced to determine pregnancy outcome (file retrieval rate-92\%). Ten patients did not deliver in AKTH. Hence one hundred and seventy four patients were used for the analysis of pregnancy outcome.

The subjects in this study were between the ages of 19 - 36 years with the mean age of $26.3 \pm 4.85$ years (Table 1). Most of them were multiparous (51.5\%) with a mean parity of $1.5 \pm 1.85$ (Table 1 ).

\begin{tabular}{ccc}
\hline Table 1. Sociodemographic factors. & \\
\hline Age (years) & Number & Percentage (\%) \\
\hline $20-24$ & 80 & 40 \\
$25-29$ & 58 & 29 \\
$30-34$ & 46 & 23 \\
35 - 39 & 16 & 8 \\
Total & 200 & 100 \\
Parity & & \\
0 (primigravida) & 76 & 38 \\
1 - 4 (multiparous) & 113 & \\
$\geq 5$ (grand multiparous) & 11 & 100 \\
Total & 200 & 10.5 \\
Social Class (Olusanya) & & 14.5 \\
1 & 21 & 50.5 \\
2 & 29 & 19.5 \\
3 & 101 & 5 \\
4 & 39 & 100 \\
5 & 200 & \\
Total & 10 & \\
\hline
\end{tabular}

Age Range $=19-36$ years; Mean $=26.3$ years \pm 4.85 ; Parity Range $=0-10$; Mean parity $=1.5 \pm 1.85$. 
Majority of the subjects had at least secondary school education and belong to social class 3 (Olusanya's Classification) (Table 1). The mean haemoglobin concentration of the study population at booking was $10.37 \pm$ 1.14 and the mean white blood cell count was $7.57 \pm 1.89$. The average gestational age was $22.6 \pm 5.60$ weeks with a range between 12 - 39 weeks, while the average gestational age at delivery was 38.4 weeks and the mean birth weight was $3.02 \pm 0.34$.

The prevalence of asymptomatic bacteriuria (ASB) in this study was 9\% (Figure 1). The commonest organisms isolated were Klebsiella and Staphylococcus saprophyticus occurring in the same proportion (44.5\% each). Escherichia coli represents the remaining 11\% (Table 2).

Most of the isolated organisms were sensitive to gentamicin (89\%), followed by ceftriaxone (56\%). Cefuroxime, ciprofloxacin and erythromycin had a sensitivity of $44 \%$ each (Table 3). Nitrofurantoin had a sensitivity of $33 \%$ while tetracycline had a sensitivity of $22 \%$ (Table 3). Ceftazidime, chloramphencol and augmentin had the least sensitivity of $11 \%$ (Table 3(a)).

Resistance to augmentin was seen in $89 \%$ of the organisms. Cotrimoxazole had a resistance of $67 \%$, chloramphenicol $44 \%$, cloxacillin $33 \%$, while ceftazidime, cefuroxime and tetracycline had $22 \%$ resistance each (Table 3(b)).

Klebsiella and Escherichia coli were 100\% sensitive to ceftriaxone, Klebsiella is $75 \%$ sensitive to cefuroxime, gentamicin and ciprofloxacin and 50\% sensitive to erythromycin and nitrofurantoin. Staphylococcus saprophyticus was $100 \%$ sensitive to gentamicin, $50 \%$ sensitive to tetracycline, $37.5 \%$ sensitive to erythromycin with intermediate sensitivity in the remaining $62.5 \%$, $25 \%$ sensitive to augmentin, and $6.3 \%$ sensitive to nitrofurantoin with intermediate sensitivity in the remaining $93.7 \%$. Escherichia coli was $100 \%$ sensitive to gentamicin nitrofurantoin ceftriaxone, ceftazidime, cefuroxime and ciprofloxacin and $50 \%$ sensitive to erythromycin (Table 3(c)).

There was no statistically significant difference in the haemoglobin concentration and white blood cell count at booking between subjects with asymptomatic bacteriuria and those without asymptomatic bacteriuria-p $=$ 0.743 and $p=0.159$ respectively. There was also no statistically significant difference in the gestational age at delivery $\mathrm{p}=0.79$, and the birth weight $\mathrm{p}=0.283$, between patients treated for asymptomatic bacteriuria and those without asymptomatic bacteriuria. However there was a statistically significant, positive correlation between the number of pus cells per high power field seen during urine microscopy and the presence of asymptomatic bacteriuria- $\mathrm{P}=0.000$ (Table 4).

There was no statistically significant difference in the presence of proteinuria $\mathrm{p}=0.52$ (Table 5). Fisher exact test was used because the frequency value of 2 is too small for application of chi-square test. None of the 18

\begin{tabular}{ccc}
\hline Table 2. Causative organisms. & & \\
\hline Causative Organism & Frequency & Percentage (\%) \\
\hline Escherichia coli & 2 & 11 \\
Klebsiella & 8 & 44.5 \\
Staphylococcus saprophyticus & 8 & 44.5 \\
Total & 18 & 100 \\
\hline
\end{tabular}

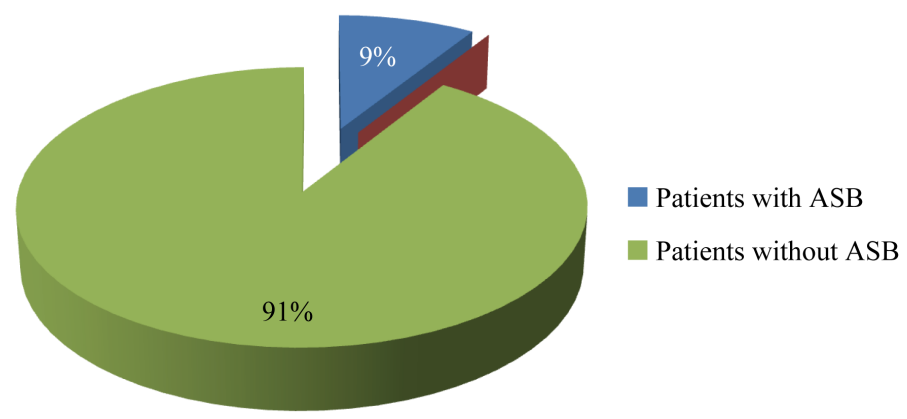

Figure 1. Patients with and without ASB. 
Table 3. Antibiotic sensitivity pattern.

(a)

\begin{tabular}{ccc}
\hline Drug sensitivity & Number of sensitive organisms & Percentage of sensitivity (\%) \\
\hline Ceftriaxone (Ci) & 10 & 56 \\
Cefuroxime (Cu) & 8 & 44 \\
Gentamicin (G) & 16 & 44 \\
Ciprofloxacine (Cf) & 8 & 11 \\
Ceftazidime (Caz) & 2 & 33 \\
Nitrofurantoin (N) & 6 & 44 \\
Erythromycin (Ery) & 8 & 22 \\
Tetracycline (T) & 4 & 11 \\
Chloramphenicol (C) & 2 & 11 \\
Augmentin (Aug) & 2 & 39 \\
\hline
\end{tabular}

There are 18 positive cultures. Some cultured organisms are sensitive to more than one drug.

(b)

\begin{tabular}{ccc}
\hline Drug resistance & Number of resistant organisms & Percentage of Resistance (\%) \\
\hline Augmentin (Aug) & 16 & 89 \\
Ceftazidime (Caz) & 4 & 67 \\
Cotrimoxaxole (Co) & 12 & 22 \\
Cefuroxime (Cu) & 2 & 44 \\
Chloramphenicol (C) & 8 & 33 \\
Cloxacillin (Cxc) & 6 & 22 \\
Tetracycline (T) & 4 & 22 \\
\hline
\end{tabular}

Some organisms are resistant to more than one drug.

(c)

\begin{tabular}{|c|c|c|c|c|c|c|c|c|c|c|c|c|}
\hline \multirow{3}{*}{ Organism } & \multicolumn{12}{|c|}{ Individual organism’s antibiogram } \\
\hline & \multicolumn{12}{|c|}{ Antibiotics } \\
\hline & $\mathrm{Ci}$ & $\mathrm{Cu}$ & G & $\mathrm{Cf}$ & $\mathrm{T}$ & $\mathrm{C}$ & Aug & Co & Cxc & $\mathrm{Caz}$ & $\mathrm{N}$ & Ery \\
\hline \multirow{3}{*}{ Klebsiella } & S-100\% & $75 \%$ & $75 \%$ & $75 \%$ & $0 \%$ & $0 \%$ & $0 \%$ & $25 \%$ & $0 \%$ & $0 \%$ & $50 \%$ & $50 \%$ \\
\hline & $\mathrm{R}-0 \%$ & $25 \%$ & $25 \%$ & $0 \%$ & $50 \%$ & $100 \%$ & $100 \%$ & $75 \%$ & $0 \%$ & $50 \%$ & $6.3 \%$ & $0 \%$ \\
\hline & IS-0\% & $0 \%$ & $0 \%$ & $25 \%$ & $50 \%$ & $0 \%$ & $0 \%$ & $0 \%$ & $100 \%$ & $50 \%$ & $43.7 \%$ & $50 \%$ \\
\hline \multirow{3}{*}{$\begin{array}{l}\text { Staphylococcus } \\
\text { Saprophyticus }\end{array}$} & $\mathrm{S}-0 \%$ & $0 \%$ & $100 \%$ & $0 \%$ & $50 \%$ & $0 \%$ & $25 \%$ & $0 \%$ & $0 \%$ & $0 \%$ & $6.3 \%$ & $37.5 \mathrm{~s} \%$ \\
\hline & $\mathrm{R}-0 \%$ & $0 \%$ & $0 \%$ & $0 \%$ & $0 \%$ & $100 \%$ & $75 \%$ & $100 \%$ & $0 \%$ & $0 \%$ & $0 \%$ & $0 \%$ \\
\hline & IS-100\% & $100 \%$ & $0 \%$ & $100 \%$ & $50 \%$ & $0 \%$ & $0 \%$ & $0 \%$ & $100 \%$ & $100 \%$ & $93.7 \%$ & $62.5 \%$ \\
\hline \multirow{3}{*}{ Escherichia coli } & S-100\% & $10 \%$ & $100 \%$ & $100 \%$ & $0 \%$ & $0 \%$ & $0 \%$ & $0 \%$ & $0 \%$ & $100 \%$ & $100 \%$ & $50 \%$ \\
\hline & $\mathrm{R}-0 \%$ & $0 \%$ & $0 \%$ & $0 \%$ & $0 \%$ & $0 \%$ & $0 \%$ & $0 \%$ & $0 \%$ & $0 \%$ & $0 \%$ & $0 \%$ \\
\hline & IS-0\% & $0 \%$ & $0 \%$ & $0 \%$ & $100 \%$ & $100 \%$ & $100 \%$ & $100 \%$ & $100 \%$ & $0 \%$ & $0 \%$ & $50 \%$ \\
\hline
\end{tabular}

S—Sensitive; R—Resistant; I-Intermediate sensitivity. 
Table 4. Comparison of some parameters (T-test).

\begin{tabular}{|c|c|c|c|c|}
\hline Parameters & $\begin{array}{l}\text { Patients with asymptomatic } \\
\text { bacteriuria }(\mathrm{X} \pm \mathrm{SD})\end{array}$ & $\begin{array}{l}\text { Patients without asymptomatic } \\
\text { bacteriuria }(\mathrm{X} \pm \mathrm{SD})\end{array}$ & $\mathrm{T}$ & $\mathrm{p}$ \\
\hline $\begin{array}{l}\text { Haemoglobin concentration } \\
\text { at booking }(\mathrm{g} / \mathrm{dl})\end{array}$ & $10.5 \pm 1.34$ & $10.4 \pm 1.12$ & 0.331 & 0.743 \\
\hline $\begin{array}{l}\text { White blood cell count at } \\
\text { booking }\left(10^{6} / \mathrm{ml}\right)\end{array}$ & $6.8 \pm 2.26$ & $7.64 \pm 1.84$ & -1.47 & 0.159 \\
\hline Urine microscopy of pus cells (/hpf) & $8.4 \pm 4.71$ & $1.8 \pm 1.86$ & 5.934 & 0.000 \\
\hline Gestational age at delivery (weeks) & $38.3 \pm 2.00$ & $38.4 \pm 3.34$ & -0.266 & 0.792 \\
\hline Birth weight (kg) & $2.94 \pm 0.36$ & $3.03 \pm 0.33$ & -1.077 & 0.283 \\
\hline
\end{tabular}

Table 5. Comparison of other parameters.

\begin{tabular}{cccc}
\hline Proteinuria & $\begin{array}{c}\text { Patientswith asymptomatic } \\
\text { Bacteriuria }\end{array}$ & $\begin{array}{c}\text { Patients without } \\
\text { asymptomatic bacteriuria }\end{array}$ & $26(14.3 \%)$ \\
Proteinuric & $2(11 \%)$ & $156(85.7 \%)$ & $172(86 \%)$ \\
Non proteinuric & $16(89 \%)$ & $182(100 \%)$ & $200(100 \%)$ \\
Total & $18(100 \%)$ & & $28 \%$ \\
\hline
\end{tabular}

Fisher exact $\mathrm{p}=0.52$.

\begin{tabular}{|c|c|c|c|}
\hline Glucosuria & & & \\
\hline Glucosuric & $0(0 \%)$ & $4(2 \%)$ & $4(2 \%)$ \\
\hline Non glucosuric & 18 (100\%) & 178 (98\%) & 196 (98\%) \\
\hline Total & 18 (9\%) & 182 (91\%) & 200 \\
\hline \multicolumn{4}{|l|}{ Parity } \\
\hline 0 (Primigravida) & 12 (15.8\%) & $64(84.2 \%)$ & 76 (100\%) \\
\hline 1 - 4 (Multiparous) & $4(3.5 \%)$ & $109(96.5 \%)$ & $113(100 \%)$ \\
\hline$\geq 5$ (Grand multiparous) & $2(18.2 \%)$ & 9 (81.8\%) & 11 (100\%) \\
\hline Total & $18(9 \%)$ & $182(91.0 \%)$ & 200 (100\%) \\
\hline \multicolumn{4}{|l|}{$X^{2}=9.523 ; \mathrm{df}=2 ; \mathrm{p}=0.009$} \\
\hline \multicolumn{4}{|l|}{ Social Class (Olusanya) } \\
\hline 1 & $2(9.5 \%)$ & $19(90.5 \%)$ & $21(100 \%)$ \\
\hline 2 & $6(20.7 \%)$ & 23 (79.3\%) & 29 (100\%) \\
\hline 3 & $4(4.0 \%)$ & $97(96.0 \%)$ & $101(100 \%)$ \\
\hline 4 & $4(10.3 \%)$ & 35 (89.7\%) & 39 (100\%) \\
\hline 5 & $2(20 \%)$ & $8(80.0 \%)$ & $10(100 \%)$ \\
\hline Total & 18 (9\%) & 182 (91\%) & 200 (100\%) \\
\hline \multicolumn{4}{|l|}{$X^{2}=9.530 ; d f=4 ; p=0.049$} \\
\hline \multicolumn{4}{|l|}{ Perinatal outcome } \\
\hline Live births & $18(100 \%)$ & $153(98.1 \%)$ & $171(98.3 \%)$ \\
\hline Stillbirths & $0(0)$ & $3(1.9 \%)$ & $3(1.7 \%)$ \\
\hline Total & 18 (100\%) & 156 (100\%) & $174(100 \%)$ \\
\hline
\end{tabular}


patients with asymptomatic bacteriuria had glucosuria giving a frequency of 0 . Therefore no test of statistical significance was applicable (Table 5).

The presence of nitrites was seen in only one subject with asymptomatic bacteriuria and none in the normal subjects. This finding was also seen with the presence of leucocytes.

Grand multiparae had the highest percentage with asymptomatic bacteriuria which was found in $18.2 \%$ of the total number of grand multiparae in the study, followed by primigravidae (15.8\% of the total number of primigravidae in the study) (Table 5). This finding was statistically significant-p $=0.009$.

Social class 2 (Olusanya's classification) had the highest percentage of subjects within the social class with asymptomatic bacteriuria $-20.7 \%$, followed by social class 5 (20\%) and social class 4 (10.3\%). Social class 1 had the least percentage (9.5\%) (Table 5). This was statistically significant $\mathrm{p}=0.049$.

There was no still birth among the patients treated for asymptomatic Bacteriuria Thus no test of statistical significance was applicable.

The null hypothesis $\left(\mathrm{H}_{0}\right.$ - The prevalence of asymptomatic bacteriuria amongst women presenting for ANC booking in AKTH is not high) is hereby accepted.

\section{Discussion}

The prevalence of asymptomatic bacteriuria in pregnancy among booking antenatal patients in this study was found to be $9 \%$, which is comparable to the prevalence of $8 \%$ found by Omole-Ohonsi and E Nwokedi in Kano in 2004 [12]. It is also comparable to 8\% prevalence rate found in Sokoto. [13] It is lower than the rates of 12.7\% [14] and 15\% [15] found in Enugu, and 86.6\% that was found in Benin city by Akerele P, Abhuliren F, and Okonofua J. [16] It is however higher than the prevalence rate of 4\% - 7\% reported in Canada [17].

The dominant organisms found to cause asymptomatic bacteriuria in this study were Staphylococcus saprophyticus and Klebsiella spp., in contrast to findings of Escherichia coli dominance by other authors [1] [12] [13]. It is however comparable to findings in other studies, where although Escherichia coli is still dominant in most cases, Staphylococcus saprophyticus and Klebsialla spp. were among the most common organisms isolated [4] [18].

The lower socio economic classes have higher prevalence of asymptomatic bacteriuria as reported by other authors [17]. In this study, social class 1 had the least prevalence of asymptomatic bacteriuria. However social class 2 had the highest prevalence of asymptomatic bacteriuria. This finding may be due to the higher proportion of women in social class two and three relative to a very low proportion of the low socio economic classes 4 and 5 in this study. This might have led to a population bias with respect to the relationship between the occurrence of asymptomatic bacteriuria and social class. It would be more representative if a study is to be conducted where the different socio-economic classes will be equally represented and compared. The difference found in this study was statistically significant.

Grand multiparous patients had the highest prevalence of asymptomatic bacteriuria in this study. This is similar to the finding in the previous study from kano [12]. This is probably due to the descent of pelvic organs associated with high parity leading to the widening of the urethral orifice and predisposing the woman to ascension of micro organisms causing bacteriuria which may progress to symptomatic urinary tract infection. The second highest group with asymptomatic bacteriuria in this study was the primigravidae group. This may be, as with malaria in pregnancy, due to impaired immunity during first pregnancy making the Primigravida more prone to infection. Expectedly, multiparous patients had the least prevalence of asymptomatic bacteriuria like they do for most pregnancy complications.

Asymptomatic bacteriuria was found to be significantly associated with pyuria in this study $(\mathrm{p}=0.000)$. This is similar to reports by some authors, who also found a positive correlation [7]. Proteinuria was not found to correlate with the presence of asymptomatic bacteriuria. This finding differs from that observed in other studies where an association was reported but no causal relationship was established [19]. This positive correlation might be due to confounding factors such as pre existing nephropathy, diabetes mellitus and sickle cell disease [19].

The presence of nitrites was seen in only one subject with asymptomatic bacteriuria and none in the normal subjects. This finding was also seen with the presence of leukocytes, with a sensitivity of $5.6 \%$ each for the two parameters, which is lower than the high values obtained in other studies that recommended the use of these tests, in combination, as alternatives to urine microscopy culture and sensitivity for the screening for asympto- 
matic bacteriuria. A positive nitrite test indicates that the causative organism is gram negative, most commonly Escherichia coli. The low sensitivity of the nitrite test may be due to the issue that the urine samples collected were not likely to be the first voided urine for that day, by the pregnant women due to inherent urinary frequency in pregnancy. The implication being that the urine has not stayed in the bladder for at least 4 hours which is the minimum required to obtain an optimal amount of urinary nitrites, and hence it is dilute [20]. In addition a nitrite test does not detect organisms unable to reduce nitrates such as enterococci and staphylococci $[20]$.

Since Staphylococcus saprophyticus constituted $44.5 \%$ of the organisms isolated from this study, it is expected that the nitrite test will have a low sensitivity. The specificity for both the nitrite test and the leukocyte esterase test was $100 \%$ as none of the normal subjects had positive results for these tests.

High sensitivity of the isolated organisms to gentamycin was found which was similar to reports from another study [21]. However its use in pregnancy is limited by its nephrotoxicity. Antibiotic sensitivity to nitrofurantoin in this study was low (33\%). This difference is likely due to the difference in the type of organisms isolated since the dominant organisms found to cause asymptomatic bacteriuria in this study were Staphylococcus saprophyticus and Klebsiella spp. However Escherichia coli showed 100\% sensitivity to the drug in this study. Most of the studies that reported high sensitivity to nitrofurantoin also reported Escherichia coli as the dominant organism isolated. Another possibility is that of emergence of resistance to nitrofurantoin, since it is widely used due to its availability affordability and relative safety in pregnancy.

Augmentin recorded the highest resistance of $89 \%$ in this study. This is the reverse of the situation in the previous Kano study where it had the highest sensitivity [12]. This may be due to development of resistance due to frequent use of the drug following the research finding. Another possibility is that this difference may be due to the change in the type of organisms mainly isolated in the two different studies. This may be evident when the study from Sokoto is compared with the previous study from Kano. Both studies isolated Escherichia coli as the commonest organism and augmentin as a drug with high sensitivity. In this study Escherichia coli had intermediate sensitivity of $100 \%$ while Klebsiella and Staphylococcus saprophyticus had $100 \%$ and $75 \%$ resistance for the drug respectively. This supports the impression that Escherichia coli has a better sensitivity for augmentin than other isolated organisms and since the prevalence of Escherichia coli was found to be low, we expect a low overall sensitivity to augmentin.

There was no statistically significant difference found in the gestational age at delivery and birth weight of the babies between patients treated for asymptomatic bacteriuria and those without asymptomatic bacteriuria in this study. This is most probably because of the antibiotic treatment given early, following the diagnosis of asymptomatic bacteriuria at booking. Other studies have also found a reduction in the rate of pregnancy complications such as low birth weight and still birth rates following early detection and treatment of asymptomatic bacteriuria [1] [8] [9]. The progression to pyelonephritis has also been found to be reduced. None of the patients treated for asymptomatic bacteriuria in this study developed pyelonephritis or recurrent asymptomatic bacteriuria.

\section{Conclusion}

The prevalence of asymptomatic bacteriuria in Aminu Kano teaching hospital is low. Staphylococcus saprophyticus and Klebsiella are the commonest organisms isolated. Grand multiparity and presence of pyuria have been found to be associated with the condition, and the serious complications associated with this condition can be avoided by early detection and antibiotic treatment of women with positive cultures.

\section{Recommendations}

1) Sreening for asymptomatic bacteriuria in AKTH should be reserved for pregnant women with higher risk of having asymptomatic bacteriuria.

2) Patients found to have asymptomatic bacteriuria in pregnancy should be treated with antibiotics based on the antibiotic sensitivity test.

3) Periodic reviews involving new research on the subject is recommended to monitor and evaluate evolving trends in asymptomatic bacteriuria.

\section{References}

[1] Lindsay, E. and Nicolle, M.D. (2003) Asymptomatic Bacteriuria. When to Screen and When to Treat. Infectious Dis- 
ease Clinics of North America, 17, 367-394.

[2] Wyngaarden, J.B., Smith, L.H., Bennett, J.C., Eds. (1992) Cecil Textbook of Medicine. 19th Edition, W.B. Saunders, Philadelphia, 593-597.

[3] Hooton, T.M., Scholees, D., Stapleton, A.E., Roberts, P.L., Winter, C., Gupta, K., et al. (2000) A Prospective Study of Asymptomatic Bacteriuria in Sexually Active Young Women. New England Journal of Medicine, 343, 991-997. http://dx.doi.org/10.1056/NEJM200010053431402

[4] Turpin, C.A., Minkah, B., Danso, K.A. and Frimpong, E.H. (2007) Asymptomatic Bacteriuria in Pregnant Women Attending Antenatal Clinic at Komfo Anokye Teaching Hospital, Kumasi, Ghana. Ghana Medical Journal, 41, 26-29.

[5] Dominic, M. (2006) Healthline Pregnancy Guide. University of Pennsylvania School of Medicine, Philadelphia.

[6] Connolly, A. and Thorp, J.M. (1999) Urinary Tract Infection in Pregnancy. Urologic Clinics of North America, 26, 779-787. http://dx.doi.org/10.1016/S0094-0143(05)70218-4

[7] Delzel, J.E. and Leferre, M.I. (2000) Urinary Tract Infections during Pregnancy. American Family Physician, 61, 713-721.

[8] Heather, C., Yun, M.D., Haizal, H. and Leonard, B.B. (2010) Bacterial Infections in Pregnancy. E-Medicine Update.

[9] Smaill, F.M. and Vazquez, J.C. (2007) Antibiotics for Asymptomatic Bacteriuria in Pregnancy. Cochrane Database of Systematic Reviews, 2, Article ID: CD000490. http://dx.doi.org/10.1002/14651858.CD000490.pub2

[10] Ijeoma, V.E., Arthur, C.I., Obioma, A.O. and Ebere, A.O. (2006) Asymptomatic Bacteriuria in Pregnant Women in Enugu, Nigeria. Tropical Journal of Obstetrics and Gynaecology, 23.

[11] Olusanya, O., Okpere, E. and Ezimokhai, M. (1985) The Importance of Social Classification in Voluntary Fertility Control in Developing Countries. West African Journal of Medicine, 4, 205-207.

[12] Omole-Ohonsi, A. and Nwokedi, E. (2008) Asymptomatic Bacteriuria in Pregnancy in Kano, Northern Nigeria. Nigerian Hospital Practice, 2, 76-79.

[13] Oyetunji, J.A., Ahmed, Y., Nwobodo, E.I., Eirede, L.R. and Ekele, B.A. (2006) Asymptomatic Bacteriuria in Pregnancy in Sokoto, Nigeria. Sahel Medical Journal, 9, 1-6. http://dx.doi.org/10.4314/smj2.v9i1.12914

[14] Obi, S.N., Onyemelukwe, N.F. and Ozumba, B.C. (2003) Significant Bacteriuria in Pregnancy in Enugu, Nigeria. Journal of College of Medicine, 8, 20-22.

[15] Ezeoma, I.V., Arthur, C.I., Okezie, O.A., et al. (2006) Asymptomatic Bacteriuria in Pregnancy in Enugu, Nigeria. Tropical Journal of Obstetrics and Gynaecology, 23, 12-13.

[16] Akerele, P., Abhuliren, F. and Okonofua, J. (2001) Prevalence of Asymptomatic Bacteriuria among Pregnant Women in Benin City, Nigeria. Journal of Obstetrics \& Gynaecology, 21, 141-144. http://dx.doi.org/10.1080/01443610020026038

[17] Hooton, T.M., Scholees, D., Stapleton, A.E., Roberts, P.L., Winter, C., Gupta, K., et al. (2000) A Prospective Study of Asymptomatic Bacteriuria in Sexually Active Young Women. New England Journal of Medicine, 343, $992-997$. http://dx.doi.org/10.1056/NEJM200010053431402

[18] Aziz, M.K., Salim, K. and Habibullah, K. (2006) Prevalence of Asymptomatic Bacteriuria in Pregnancy. Pakistan Journal of Medical Sciences, 22, 162-166.

[19] Joanne, L.C., Charles, R., Tomson, V., Paul, E.S. and Edmund, J.L. (2006) Does Urinary Tract Infection Cause Proteinuria or Microalbuminuria? A Systematic Review. Nephrology Dialysis Transplantation, 21, 3031-3037. http://dx.doi.org/10.1093/ndt/gfl373

[20] Fitzgerald, M.A. and Nettina, S.M. (2002) Urinary Tract Infection: Providing the Best Care. Available on Wikipedia.

[21] Gilbert, D.N., Moellering, R.C., Eliopoulos, G.N. and Sande, N.A. (2005) Sanford Guide to Antimicrobial Therapy. 32nd Edition, Antimicrobial Therapy, Inc., Hyde Park, VT, 72-73. 